\title{
Investigation and Analysis of Influencing Factors of Occupational Ethics Education for Students in Health Vocational Colleges
}

\author{
Liu suqin ${ }^{1, \text { a * }}$ \\ ${ }^{1}$ Jiangsu Vocational College of Medicine, Yancheng, Jiangsu, 224005 \\ a*676404859@qq.com
}

\begin{abstract}
Keywords: Health vocational colleges; Students; Professional ethics education; Investigation and analysis.
\end{abstract}

\begin{abstract}
Based on the investigation of students and teachers in some health vocational colleges in Jiangsu Province, this paper makes a thorough analysis of the importance attached to professional ethics education, the level of students' understanding of professional ethics and the contents, approaches, teachers and evaluation of professional ethics education in health vocational colleges, and puts forward some suggestions for improving the students' profession in health vocational colleges.
\end{abstract}

\section{Introduction}

Health career is a high-risk service industry. With the continuous development and progress of human society, people's demands for health services are also getting higher and higher. As implementers of the health service, whether they have good professional ethics is directly related to the quality of life and health of the service object. Health vocational colleges are one of the main positions for the health sector to train a large number of practical health professionals. At present, there are various phenomena deviating from professional ethics in the health profession, which puts forward higher requirements for health vocational colleges, that is, to train a large number of high-quality, skilled workers to meet the needs of modern social development for the health profession, at the same time, to strengthen the education of students' professional ethics. Aiming at this problem, in order to better understand the relevant factors affecting the occupational ethics education of students in health vocational colleges, the research group carried out a survey in health vocational colleges in Jiangsu Province.

Object and method of investigation. The present situation of students'professional ethics education in Jiangsu Medical Vocational College, Suzhou Health Vocational College and Jiangsu Jiankang Vocational College, which had been established in Jiangsu Province for more than five years, was investigated.

1. Using the method of random systematic sampling, the first and second grade students of seven same specialties in three health vocational colleges were systematically numbered, and then 50 students were randomly selected from each of the same specialties in each school to investigate the current situation of occupational ethics education (that is, 350 first and second grade students were selected from three health vocational colleges respectively). Among them, 50 were nurses, 50 were pharmacists, 50 were medical imaging technology, 50 were rehabilitation treatment technology, 50 were medical laboratory technology, 50 were health information management, 50 were drug management and management.

2. Based on the fact that all the students in the three health vocational colleges entered the internship unit in the third year of their entrance, and the professional ethics education situation of these students is different from that of the students in the first and second grade, therefore, the professional ethics education of the interns was investigated separately in this study. Using the method of random systematic sampling, seven internships of the same specialty in three health vocational colleges were systematically numbered. Five internships were randomly sampled from each school, and six interns were randomly sampled from each internship to conduct a questionnaire survey (that is, 210 interns were sampled from three health vocational colleges respectively). Students, including 30 nursing, 
pharmaceutical 30, medical imaging technology 30, rehabilitation treatment technology 30, medical laboratory technology 30 , health information management 30, drug management 30 .

3. Ten teachers ( 30 teachers) of occupational ethics courses were randomly selected from three health vocational colleges to conduct on-the-spot interviews in three sessions.

Investigation and analysis of influencing factors. Questionnaire recovery: 1050 questionnaires were sent out to students of 7 majors. All questionnaires were recovered. The effective rate was 95.6\%. A total of 630 intern questionnaires were issued, and 616 valid questionnaires were received, with an effective rate of $97.8 \%$.

Table 1 main ways for students to receive professional ethics education information

\begin{tabular}{|c|c|c|c|c|}
\hline \multirow{2}{*}{ option } & $\begin{array}{c}\text { Counselor or } \\
\text { employment } \\
\text { guidance teacher }\end{array}$ & $\begin{array}{c}\text { Ideological and } \\
\text { political education } \\
\text { teacher }\end{array}$ & $\begin{array}{c}\text { Professional } \\
\text { teacher }\end{array}$ & $\begin{array}{c}\text { Schools do not employ } \\
\text { teachers who specializes } \\
\text { in professional ethics } \\
\text { education }\end{array}$ \\
\hline Proportion & $43 \%$ & $39 \%$ & $13 \%$ & $5 \%$ \\
\hline
\end{tabular}

1. Schools do not attach enough importance to professional ethics education.

(1) Establishment of Professional Ethics Education Funds: Teachers interviewed by three health vocational colleges said that the schools did not separate out the funds for professional ethics education and did not set up separate funds for professional ethics education, indicating that the school did not invest enough in financial resources for professional ethics education [2].

(2) Professional ethics courses offered: from the interviews with teachers, it is known that the professional ethics education in three health higher vocational colleges is mainly carried out through the "two courses" and "ethics" courses. The students'class hours are about 140 hours during the school period, while the Ministry of Central Propaganda and the Ministry of Education stipulate that the "two courses" for college students should not be less than 128 hours. It can be seen that there are fewer classes of occupational ethics in 3 health vocational colleges. The survey results of teachers in 3 health vocational colleges were $p>0.05$, and the difference was not statistically significant. The results show that the school overemphasizes the specialty, the professional knowledge system and teaching materials are complete, and the humanities curriculum of professional ethics education is very deficient.

(3) Professional ethics curriculum teachers team building: $43 \%$ of the students believe that "professional ethics education received mainly from counselors or career guidance teachers", the specific survey data as shown in Table 1. The results show that there are still some shortcomings in the allocation of professional teachers in professional ethics education. Counselors and moral educators are too busy with daily affairs to ignore the urgency of students to receive professional ethics education.

(4) professional ethics education activities: the survey results of different majors are shown in Table 2. Statistical analysis by rank sum test showed that there was no significant difference in professional ethics education activities among different specialties in health vocational colleges, which indicated that the three schools had basically the same special activities, and the frequency of activities was not high, so they did not carry out professional ethics education through activities. 
Table 2 professional ethics activities conducted by different majors

\begin{tabular}{lccc}
\hline \multirow{2}{*}{ major } & \multicolumn{3}{c}{ Professional activities of professional ethics education } \\
\cline { 2 - 4 } & often & rarly & none \\
\hline Nursing & 69 & 75 & 4 \\
pharmacy & 57 & 82 & 4 \\
Medical imaging technology & 52 & 79 & 10 \\
Rehabilitation technology & 63 & 76 & 3 \\
Medical Laboratory Technology & 56 & 82 & 4 \\
Health information management & 54 & 84 & 6 \\
Drug operation and management & 53 & 83 & 8 \\
\hline
\end{tabular}

$\mathrm{X}^{2}=7.116, \quad \mathrm{P}=0.310$

2. Educated people do not have a high level of understanding of professional ethics.

(1) Learning professional ethics is helpful for future work: $85 \%$ of students choose "no help" and "uncertain". 15\% of students choose "very helpful" or "relatively helpful". This shows that students do not have enough understanding of professional ethics.

(2) The necessity of offering professional ethics education courses: $90 \%$ of the students think it is "very necessary" and "necessary". 8\% of the students choose "uncertain". 2\% of the students choose "unnecessary". This data shows that the students of health vocational colleges in Jiangsu Province have changed their ideas on occupational ethics education subjectively. Most of the students think that it should be carried out in health vocational colleges. Therefore, college students have a strong urgency for professional ethics education and are eager to be nurtured by good health professional ethics. However, due to some students' superficial knowledge of the medical profession, their motivation to choose a major tends to meet the requirements of their own interests, and deviates from the requirements of the times (the results of the questionnaire survey are shown in Table 3, so it is lacking. Lack of dedication and lack of social responsibility.

Table 3 professional choice motivation

\begin{tabular}{|l|l|l|l|l|l|}
\hline Categories & $\begin{array}{l}\text { determined } \\
\text { by parental } \\
\text { influence }\end{array}$ & $\begin{array}{l}\text { fewer } \\
\text { competitors }\end{array}$ & easy to get job & $\begin{array}{l}\text { interesting and } \\
\text { learning } \\
\text { meaningful }\end{array}$ & is be adjusted \\
\hline ratio & $10 \%$ & $15 \%$ & $60 \%$ & $12 \%$ & $3 \%$ \\
\hline
\end{tabular}

(3) Understanding of College Students'professional ethics education: 36\% of students choose "university is professional education, the professional ethics requirements are not the same, can not use a unified teaching content for education"; $27 \%$ of students choose "college students' professional ethics education is low education, college education is high education"; Students choose "college students'professional ethics education and employment guidance education confuse each other, there is no clear guiding objectives", $3 \%$ of students choose "unclear". This data shows that although students in health vocational colleges have a demand for professional ethics education, but there is still a one-sided understanding of professional ethics education, can not be a comprehensive and development perspective on this issue.

(4) Understanding of future occupational ethics in health industry: Students'understanding of future occupational ethics in health industry is shown in Table 4. This shows that teachers seldom involve in the 
contents of health professional ethics education in the basic medical courses and professional courses, and do not combine the professional ethics education with the professional courses.

Table 4. The level of understanding of basic occupational ethics required for the future health sector.

\begin{tabular}{|l|c|l|l|c|}
\hline Option & heard of & know & know well & don't know \\
\hline Proportions & $43 \%$ & $39 \%$ & $13 \%$ & $5 \%$ \\
\hline
\end{tabular}

To sum up, we can see that schools, students and teachers have not attached great importance to professional ethics education, we must start from these three aspects, strengthen the vocational ethics education in health vocational colleges.

\section{References}

[1] B. Zhou: China Vocational and Technical Education, Vol. 11(2009), p. 31

[2] C. D. Deng, X. W. Xiao: Forum on Education and Teaching, Vol. 5(2015), p. 58.

[3] J. Chen : Modern Medical and Health, Vol. 31(2015) No.5, p. 776-778.

[4] Y. Wang: Science and Technology Innovation Report, Vol. 18 (2013), p. 161.

[5] X. J. Bi: Challenges and Countermeasures of Medical Ethics Education in Medical Colleges [D] [Master's Degree Dissertation]. Shijiazhuang: Hebei Normal University, 2011.

[6] C. Wang: Heihe Journal, Vol. 3 (2012), p. 11-13.

[7] C. P. Zhu: Health vocational education, Vol. 21 (2012), p. 22-24 